JMI Vol. 42 No. 2, Desember 2020

METAL INDONESIA

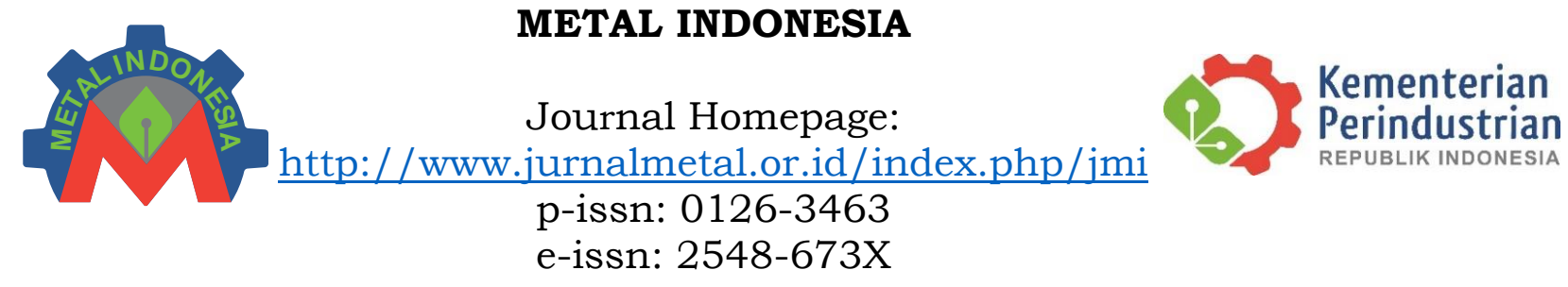

\title{
PERANCANGAN MESIN AUTO SPRAY UNTUK CLEANING CANDLE FILTER
}

\section{DESIGN AUTO SPRAY MACHINE FOR CLEANING CANDLE FILTER}

\author{
Amri Abdulah $^{1 *}$, Apang Djafar Shieddieque ${ }^{1}$, Dede Ardi Rajab ${ }^{1}$, Sukarman$^{1}$, \\ Choirul Anwar ${ }^{1}$ \\ ${ }^{1}$ Program Studi Teknik Mesin, Sekolah Tinggi Teknologi Wastukancana \\ Jalan Cikopak No 53 Purwakarta 41151,Jawa Barat-Indonesia \\ E-mail : amri@stt-wastukancana.ac.id \\ *Kontributor Utama
}

\begin{abstract}
Abstrak
Penelitian ini membahas perbaikan proses penyemprotan pada tahap pembersihan candle filter di PT $\mathrm{XYZ}$, yaitu permasalahan proses penyemprotan manual pada candle filter yang tidak efisien. Berdasarkan permasalahan tersebut maka perlu dilakukan proses penyemprotan dengan mesin. Penelitian ini membahas tentang perancangan mesin penyemprot otomatis candle filter untuk mengurangi waktu pengerjaan. Mesin ini dirancang untuk berbagai ukuran candle filter, dan mesin dapat membersihkan candle filter dari luar dan dalam secara bersamaan. Hasil perancangan yaitu mesin auto spray memiliki putaran untuk penggerak nosel yaitu 596,1 Rpm dan pemutar candle filter $480 \mathrm{Rpm}$. Kecepatan putaran dirancang dengan RPM yang dapat disesuaikan dan dikontrol oleh inverter pada panel. Mesin auto spray memiliki konstruksi yang tahan korosi dan kokoh dengan spesifikasi mesin sepanjang $3005 \mathrm{~mm}$ x lebar $515 \mathrm{~mm}$ x tinggi $1215 \mathrm{~mm}$. Proses penyemprotan menghemat waktu yaitu mencapai $60 \%$ yang diperoleh dari perhitungan proses penyemprotan secara manual, dan menggunakan mesin otomatis masing-masing adalah 25 menit 10 menit. Dari segi kualitas, hasil penyemprotan menggunakan mesin juga lebih baik. Dari 40 sampel yang diuji dari setiap proses, nilai rata-rata partikel saat menggunakan mesin, dan secara manual masing-masing adalah 5,36 gram dan 23,6 gram.
\end{abstract}

Kata Kunci: nozzle, spray, cleaning, candle, filter

\begin{abstract}
This research discusses the spray process's improvement at the filter candle cleaning stage at PT XYZ. The spray at the filter candle has an inefficient manual process. Based on this problem, it is necessary to do the spray process by machine. This research discusses the design of an auto spray machine for candle filters to reduce processing time. The machines are designed for various sizes of filter candles, and they can clean the candle filter from the outside and the inside simultaneously. The auto spray machine's results have a rotational speed of the nozzle spray propulsion of 596.1 Rpm and the filter candle player 480 Rpm. Rotation speed was designed by adjustable RPM and controlled by the inverter on the panel. The auto spray machine has a corrosion-resistant and robust construction with a $3005 \mathrm{~mm}$ long machine specification $\times 515 \mathrm{~mm}$ wide $x 1215 \mathrm{~mm}$ high. The spray process saves time by reaching 60\%, which is obtained from the calculation of the spray process manually, and using an automatic machine is 25 minutes and 10 minutes, respectively. From a quality point of view, the machine spray results are also better. The 40 samples tested from each
\end{abstract}


process, the mean values of particles when using the machine, and manually were 5.36 grams and 23.6 grams, respectively.

Keywords : Nozzle,Spray,Cleaning,Candle,Filter

\section{PENDAHULUAN}

Di Industri polimerisasi banyak menggunakan saringan (filter) yang fungsinya untuk menyaring kotoran atau partikel yang terbawa oleh polimer (Raehse 1989), ada bermacam - macam model saringan untuk produk polimer salah satunya yaitu tipe candle.

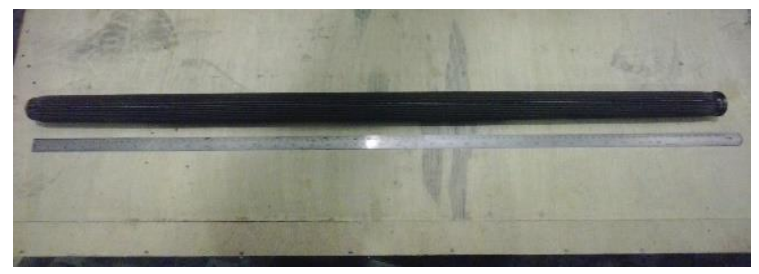

Gambar 1. Candle filter

Candle filter merupakan saringan yang bentuknya menyerupai lilin yaitu bulat dan panjang(Ushiki and Tien 1989), fungsinya yaitu untuk menyaring kotoran pada waktu proses polimerisasi sedang berlangsung dari satu tangki reaktor ke tangki reaktor lainnya. Proses pembersihan filter terdiri dari 8 tahapan yaitu :
a. Hydrolisis
e.Ultrasonic machine
b. Spray
c. Chemical proses
d. Spray
f. Drying oven
g. Test deposit
h. Bubble test

Tahapan ke 2 dan ke 4 yaitu tahapan spray saat ini masih dilakukan secara manual, spray manual adalah proses pembersihan candle filter dengan cara menyemprotkan air bertekanan tinggi (water jet) ke bagian luar maupun bagian dalam candle filter, semburan air yang keluar dari nozzle-gun di arahkan langsung oleh operator. Proses spray 1 buah candle filter memerlukan waktu selama 25 menit jika dilakukan secara manual. Melihat latar belakang proses pembersihan candle filter diatas maka perlu dilakukan suatu analisa dalam proses pembersihan untuk menghemat waktu pengerjaan. Penelitian dan perancangan mesin untuk menghemat waktu pengerjaan proses spray dilakukan di lokasi pengguna yang membutuhkan yaitu PT XYZ yang bergerak dalam memproduksi polimer di daerah Purwakarta.

\section{TINJAUAN PUSTAKA}

Pembersihan untuk polymer textile dan bottle grade filter pada dasarnya menghilangkan kontaminan polimer, $\mathrm{TiO} 2$ dan additive di mesh pack filter, ada dua metode yang lazim digunakan untuk menghilangkan polimer pada mesh pack filter yakni dengan proses hidrolisis dan proses perendaman menggunakan TEG (Jo Joong-yeon et al. 2013). Titanium dioksida (TiO2) dan additive lainnya dihilangkan dengan perendaman pada larutan kimia didalam tangki. Untuk mengefektifkan agar partikel-partikel kontaminan keluar dari mesh pack filter digunakan proses fisik, yakni proses spray menggunakan water jet(Guha, Barron, and Balachandar 2011), (Cirqueira, Tanabe, and Aguiar 2019) dan proses menggunakan frekuensi getaran pada ultrasonic machine.

\section{a. Hidrolisis}

Definisi hidrolisis adalah reaksi kimia yang memecah molekul air (H2O) menjadi kation hidrogen $(\mathrm{H}+)$ dan anion hidroksida $\left(\mathrm{OH}^{-}\right)$ melalui suatu proses kimia. Proses ini biasanya digunakan untuk memecah polimer tertentu, terutama yang dibuat melalui polimerisasi tumbuh bertahap (step-growth polimerization). Kata "hidrolisis" berasal dari bahasa Yunani hydro "air" + lysis "pemisahan"(Bitar 2019) Sistem ini menggunakan cairan TEG yang di panaskan di tangki dengan suhu $280^{\circ} \mathrm{C}$ selama 12 jam, dengan pengaturan waktu dan suhu tersebut diharapkan kontaminan polimer yang menempel di filter akan larut oleh TEG.

\section{b. Spray pertama}

Pada proses spray pertama yaitu menggunakan water jet, tekanan air disetting 100 bar dan air yang bertekanan tersebut diarahkan ke permukaan luar dan bagian dalam candle filter. 


\section{c. Chemical Proses}

Untuk menghilangkan $\mathrm{TiO} 2$ yang masih tertinggal di mesh pack filter maka di reaksikan dengan larutan $\mathrm{NaOH} 13.5 \%$ dengan cara di rendam dan dipanaskan pada suhu $110^{\circ} \mathrm{C}$ selama 8 jam yang menghasilkan sodium hydroxytitanat (NaHTiO3) berbentuk gelatinous yang mudah di spray dengan air. Larutan yang dipakai adalah Osbond 673 untuk proses pembersihan filter dari CP1 dan CP3, sedangkan SPC W-38 khusus untuk proses pembersihan filter $\mathrm{CP} 2$, keduanya harus diperbaharui bila kandungan $\mathrm{NaOH}$ dibawah $13.5 \%$. Pembuatan larutan baru di perlukan jika larutan sebelumnya sudah dipakai 15 Cycle. Larutan baru di buat dengan cara memasukan serbuk Osbond 673 sebanyak $200 \mathrm{Kg}$ ke dalam tangki 33-1101 sedangkan SPC W-38 sebanyak $200 \mathrm{~kg}$ kedalam tangki 33-1102, yang sudah diisi dengan demineralized water sebanyak 800 liter dan larutan di perbaharui dengan memasukan serbuk Osbond 673 atau SPC W-38 sebanyak masing-masing $50 \mathrm{~kg}$ ke dalam larutan pada cycle 8.

\section{d. Spray kedua}

Spray kedua prosesnya sama dengan spray pertama yaitu menggunakan water jet dengan tekanan disetting 100 bar dan air yang bertekanan tersebut diarahkan ke permukaan luar dan bagian dalam candle filter.

\section{e. Menggunakan gaya getar}

Partikel yang berada di mesh pack filter digetarkan oleh elektroda sehingga timbul getaran dengan frekuensi $45 \mathrm{kHz}$ dan partikel yang menempel akan keluar akibat gaya getar. Alat ini dinamakan "Ultrasonic Machine".

\section{f. Drying Oven}

Tujuan dari pengeringan candle filter menggunakan drying oven yaitu agar terjadi penguapan air yang masih terdapat saat proses spray pada candle filter sehingga berat deposit yang tertinggal di filter dapat diketahui, ada dua peralatan yang digunakan untuk pengeringan yaitu dengan menggunakan drying oven dan preheating cabinet.

\section{g. Deposite test}

Siapkan timbangan untuk menimbang candle filter, timbangan tersebut sebelumnya dikalibrasi terlebih dahulu, lalu satu per satu timbang candle filter dan catat pada buku laporan deposite test. Selanjutnya data berat hasil penimbangan dibandingkan dengan berat candle filter awal. Apabila setelah di timbang berat candle filter lebih dari 5 gram dari cycle sebelumnya maka filter tersebut harus di lakukan proses pembersihan ulang sampai kenaikan beratnya tidak melebihi 5 gram dari cycle sebelumnya.

\section{h. Bubble Test}

Tujuan utama dari proses bubble test adalah untuk mengetahui kerusakan/ kebocoran mesh pack dari candle filter (Nvbop 2018) (Hayashi, Douhara, and Kashino 2014). Prinsip dasarnya adalah mesh pack dari candle filter direndam pada larutan isopropil alkohol yang diatur ketinggian permukaannya. Ujung bagian bawah candle filter dipasang adaptor yang dilengkapi pipa untuk mengalirkan udara dari bagian dalam mesh pack, selanjutnya diatur kecepatan aliran udara yang menuju ke candle filter, dari bubble flow yang dihasilkan langkah selanjutnya dibandingkan dengan bubble flow dari candle filter yang baru.

\section{PERANCANGAN}

Sebelum merancang suatu produk dibutuhkan konsep awal rancangan dari produk tersebut (Suwandi, Maulana, and Rhapsody 2017).

Dalam pembuatan mesin auto spray, yang pertama dilakukan yaitu merancang bentuk, dimensi serta ukuran alat yang sesuai dengan kebutuhan pengguna dan kebutuhan kualitas fungsi mesin.

Konsep desain mesin untuk memenuhi kebutuhan pengguna dapat dilihat pada Tabel 1 diatas. Kualitas pembersihan candle filter pada tahapan spray yang dilakukan secara manual dipengaruhi juga oleh faktor kesalahan manusia yaitu di antaranya:

a. ketidakrataan proses spray yang dilakukan langsung oleh manusia,

b. ketidak seragaman proses spray yang dilakukan oleh operator yang berbeda. 
Tabel 1. Kebutuhan dan konsep desain

\begin{tabular}{|c|c|}
\hline Kebutuhan & Konsep mesin dan alat yang digunakan \\
\hline $\begin{array}{l}\text { Mudah } \\
\text { operasikan }\end{array}$ & $\begin{array}{l}\text { Mematikan dan menghidupkan mesin } \\
\text { menggunakan tombol On/Off yang } \\
\text { disimpan dalam satu panel. }\end{array}$ \\
\hline $\begin{array}{ll}\text { ktu dapat } \\
\text { cur }\end{array}$ & Waktu diatur menggunakan timer \\
\hline \multirow{2}{*}{$\begin{array}{l}\text { Kecepatan } \\
\text { putaran dapat } \\
\text { diatur }\end{array}$} & $\begin{array}{l}\text { Pengatur putaran motor } 1 \text { menggunakan } \\
\text { inverter, Motor ini untuk menggerakan } \\
\text { nozzle spray. }\end{array}$ \\
\hline & $\begin{array}{l}\text { Pengatur putaran motor } 2 \text { juga } \\
\text { menggunakan inverter, Motor ini untuk } \\
\text { memutarkan candle filter }\end{array}$ \\
\hline $\begin{array}{l}\text { Pemasangan } \\
\text { dan Pelepasan } \\
\text { mudah } \\
\text { dilakukan }\end{array}$ & $\begin{array}{l}\text { Mesin menggunakan cekam universal } \\
\text { sehingga tidak diperlukan pemusatan } \\
\text { benda kerja (Centering) pada mesin. }\end{array}$ \\
\hline Serbaguna & $\begin{array}{l}\text { Mesin dapat digunakan untuk candle } \\
\text { filter dengan ukuran berbeda karena } \\
\text { kepala pemutar menggunakan pegas } \\
\text { sehingga candle filter yang panjang } \\
\text { dan pendek dapat secara cepat } \\
\text { dipasang. }\end{array}$ \\
\hline Tahan lama & $\begin{array}{l}\text { Agar umur pakai mesin bertahan lama, } \\
\text { maka peralatan terutama rangka mesin } \\
\text { dibuat menggunakan bahan dasar dari } \\
\text { stainless steel. }\end{array}$ \\
\hline Kualitas baik & $\begin{array}{l}\text { Peningkatan kualitas hasil spray yaitu } \\
\text { dengan melakukan pemutaran candle } \\
\text { filter, ini dimaksudkan untuk } \\
\text { meminimalisir ketidakrataan proses } \\
\text { spray dan membantu pelepasan partikel } \\
\text { partikel. Kedua, dengan menggunakan } \\
\text { mesin arah semprotan air melalui nozzle } \\
\text { dapat secara kontinyu mengenai } \\
\text { permukaan candle filter. }\end{array}$ \\
\hline $\begin{array}{l}\text { Kecepatan } \\
\text { pengerjaan }\end{array}$ & $\begin{array}{l}\text { Kecepatan proses spray dilakukan } \\
\text { dengan menghubungkan gerakan nozzle } \\
\text { vertikal dan nozzle horisontal sehingga } \\
\text { dapat bergerak bersamaan. }\end{array}$ \\
\hline
\end{tabular}

Setelah dilakukan wawancara kebutuhan mesin dan permasalahan yang perlu diperbaiki maka selanjutnya yaitu melakukan pendataan candle filter.

\section{Pengambilan Data Candle Filter}

Mesin auto spray yang dirancang, ukurannya menyesuaikan dengan ukuran candle filter yang akan di spray. Dari pendataan dilapangan yang dapat dilihat pada Tabel 2 . diambil kesimpulan bahwa panjang mesin autospray yang akan dibuat minimal $1000 \mathrm{~mm}$ dan maksimal $1020 \mathrm{~mm}$.
Tabel 2. Ukuran candle filter

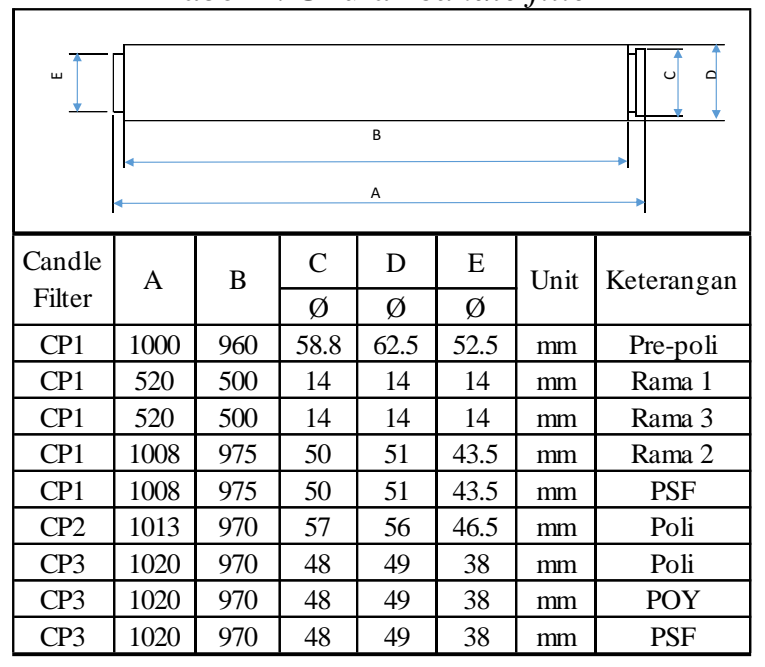

\section{Membuat Gambar Rancangan}

Membuat gambar rancangan atau gambar kerja, Pembuatan gambar kerja diterapkan pada gambar 2 dimensi disertai ukuran selengkap mungkin, Melakukan perhitungan terhadap komponen-komponen alat yang dirancang seperti rasio putaran atau kekuatan bahan. Komponen komponen mesin auto spray

1. Motor listrik penggerak nozzle

Mesin auto spray menggunakan dua motor listrik, motor yang pertama untuk menggerakan maju dan mundur nozzle.

Putaran motor listrik dirubah menjadi gerak maju dan mundur menggunakan poros berulir dan mur (nozzle adaftor) dengan spesifikasi motor sebagai berikut:
a. Merek
$=$ Bharat bijle
b. Volt
$=415$
c. Putaran maksimum
$=1395 \mathrm{Rpm}$
d. Daya
$=0.75 \mathrm{Kw}$
e. Frekuensi
$=50$ Hertz .

Kecepatan putaran yang direncanakan:
Reduksi putaran sabuk-v $\quad=\frac{n_{1}}{n_{2}}=\frac{d_{2}}{d_{1}}$
Putaran input (n1)
$=1395 \mathrm{Rpm}$
Diameter puli motor (d1)
$=53 \mathrm{~mm}$
Diameter puli Shaft-screw $(\mathrm{d} 2)=124 \mathrm{~mm}$

$\frac{1395}{n_{2}}=\frac{124}{53}, \quad n_{2}=596,1 \mathrm{rpm}$ 


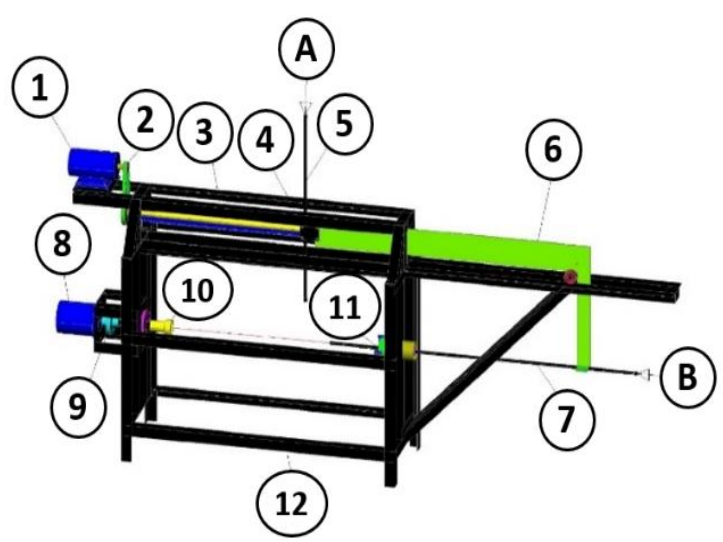

Gambar 2. Rancangan mesin auto spray

Keterangan gambar:

1. Motor penggerak

2. Puli dan sabuk-v

3. Poros

4. Adaftor nozzle spray

5. Nozzle vertikal

6. Pelat pembawa

A. Inlet water

7. Nozzle horisontal

8. Motor penggerak

9. Kopling flens

10. Kepala pemutar

11. Cekam universal

12. Rangka mesin

B. Inlet water

\section{Puli dan sabuk-v (Pulley and V-Belt)}

Bagian penggerak nozzle, sistem transmisinya menggunakan puli dan sabuk-v yang komponennya terdiri dari motor listrik, puli 1 , puli 2 , sabuk-v dan poros. Puli dan sabuk-v adalah alat untuk meneruskan daya dari penggerak ke yang digerakan, mekanisme yang bekerja pada sistem transmisi ini berawal dari motor listrik ditransmisikan ke Puli 1 yang kemudian menggunakan sabuk-v, daya ditransmisikan ke Puli 2 sehingga poros berulir (shaft screw) dapat berputar.

\section{Poros berulir (Shaft screw)}

Shaft screw yang digerakan oleh motor berfungsi untuk menggerakan nozzle horisontal dan vertikal yang terikat di adaftor. Pergerakan nozzle spray yaitu maju dan mundur dengan batas tertentu yang disesuaikan dengan panjang candle filter, Diameter shaft screw pada posisi puli yaitu $\varnothing 25 \mathrm{~mm}$, Pada posisi ulir Diameter Mayor (DM) $=\varnothing 30 \mathrm{~mm}$, Diameter Pitch $(\mathrm{Dp})=28,5 \mathrm{~mm}$, Diameter Minor $(\mathrm{Dm})=\emptyset 27 \mathrm{~mm}$, Pitch $=\mathrm{L}=$ $3 \mathrm{~mm}$.

\section{Adaftor nozzle spray}

Adaftor nozzle spray merupakan pasangan dari poros berulir (Shaft screw) seperti halnya Baut dan Mur, nozzle spray vertikal terikat langsung di adaftor, sedangkan untuk mengikat nozzle spray horisontal pada adaftor menggunakan alat bantu berupa pelat pembawa sehingga kedua nozzle dapat bergerak bersamaan.

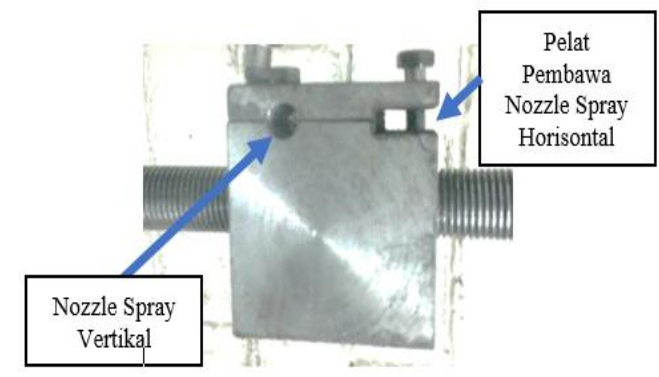

Gambar 3. Adaftor nozzle spray

5. Nozzle spray vertikal

Nozzle spray vertikal berfungsi untuk penyemprotan candle filter bagian luar.

6. Pelat pembawa

Pelat pembawa berfungsi mengikat nozzle spray horisontal.

\section{Nozzle spray horisontal}

Nozzle spray horisontal berfungsi untuk penyemprotan candle filter bagian dalam.

\section{Motor penggerak candle filter}

Motor listrik ini berfungsi untuk memutar, sehingga candle filter berputar dengan kecepatan tinggi yang akan mendapatkan hasil spray yang merata dan selain itu dengan adanya gaya yang dihasilkan oleh putaran motor dapat mempercepat proses spray dari candle filter. Motor yang digunakan mempunyai spesifikasi sebagai berikut :

$\begin{array}{ll}\text { a.Merek } & =\text { Allweiler AG } \\ \text { b. Volt } & =380 \\ \text { c. Putaran Maksimal } & =3000 \mathrm{Rpm} \\ \text { d. Daya } & =0,75 \mathrm{~kW} \\ \text { e. } \text { Frekuensi } & =50 \text { Hertz } .\end{array}$

Motor ini dilengkapi dengan pengatur kecepatan putaran yaitu menggunakan inverter (Siemens 2006) agar memudahkan operator dalam 
menaikan atau menurunkan kecepatan putaran motor.

Putaran motor yang direncanakan :

$\begin{array}{ll}\text { Putaran output motor } & =480 \mathrm{Rpm} \\ \text { Putaran maksimal (n1) } & =3000 \mathrm{Rpm} \\ \text { Frekuensi maksimal (f1) } & =50 \mathrm{~Hz}\end{array}$

Putaran yang direncanakan $(\mathrm{n} 2)=480 \mathrm{Rpm}$ frekuensi yang digunakan (f2) = ?

$f 2=\frac{480}{3000} \times 50=8 \mathrm{~Hz}$

\section{Kopling flens kaku}

Bagian pemutar candle filter, sistem transmisinya menggunakan kopling flens kaku sehingga putaran motor listrik langsung diteruskan ke poros penggerak candle filter, komponennya terdiri dari motor listrik, kopling flens kaku, poros, dan kepala pemutar. Kopling flens (JIS-B 1451-1962) dengan diameter poros 24 $\mathrm{mm}$ maka didapat ukuran kopling flens kaku, yaitu : $A=112, B=75, C=45, L=40, n=4, F=$ $11.2 \mathrm{~mm}$, Bahan flens $=$ FC 20. (Sularso and Suga 1996)

\section{Kepala Pemutar candle filter}

Kepala pemutar dalam mesin auto spray berfungsi untuk memutar dan menahan beban dari candle filter.

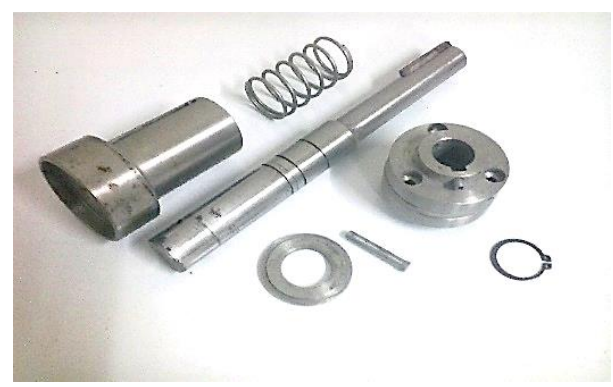

Gambar 4. Kepala pemutar dan asesoris

Ujung benda kerja lainnya di jepit oleh cekam (universal chuck), pada bagian kepala pemutar ada tambahan pegas (spring) sehingga perbedaan panjang candle filter dapat di atasi.

A. Perhitungan ukuran dan beban pegas yang diperlukan (Sigley, Mitchel, and Harahap, n.d.):
a. Beban maksimum $\mathrm{W} 1=10 \mathrm{~kg}$
b. Lendutan $(\delta) \quad=25-50 \mathrm{~mm}$
c. Panjang bebas $(\mathrm{H}) \quad=72 \mathrm{~mm}$

d. Diameter lilitan (D) $=37 \mathrm{~mm}$

e. Diameter kawat (d) $\quad=2,9 \mathrm{~mm}$

Bahan kawat yang digunakan adalah bahan kawat tahan korosi di pilih SUS 27 dengan data sebagai berikut :

Modulus geser $\mathrm{G}=7500(\mathrm{~kg} / \mathrm{mm} 2)$

$\tau \mathrm{a}=70, \tau \mathrm{d}=70 \times 0,8=56(\mathrm{Kg} / \mathrm{mm} 2)$

Tegangan geser $(\mathrm{t})$ :

$\mathrm{t}=\mathrm{K}\left[\frac{8 \mathrm{DW}}{\pi \mathrm{d}^{3}}\right]$

Harga indeks $c=D / d=37 / 2,9=12,75$

Faktor tegangan dari wahl :

$\mathrm{K}=\frac{4 \mathrm{c}-1}{4 \mathrm{c}-4}+\frac{0,615}{\mathrm{c}}=1,11$

$t=1,11\left[\frac{8 \times 37 \times 10}{3,14 \times 2,9^{3}}\right]$

$\mathrm{t}=42,90(\mathrm{~kg} / \mathrm{mm} 2)$

$t<t_{d}, 42,90<56$, (Baik untuk digunakan)

Jumlah Lilitan Aktif (n) :

$\begin{aligned} \delta & =\left[\frac{8 n \times D^{3} \times W}{d^{4} \times G}\right] \\ 50 & =\left[\frac{8 n \times 37^{3} \times 10}{2,9^{4} \times 7500}\right] \\ n & =6,54--\rightarrow 6\end{aligned}$

Lendutan total $\left(\delta_{\text {total }}\right)$ :

$\delta=50 x\left[\frac{6}{6,54}\right]$

$\delta=45,87-\rightarrow(25-50)$, Baik

Lendutan effektif $\left(\delta_{\text {Efektif }}\right)$ :

$45,87-(72-54,25)=28,12 \mathrm{~mm}$

Konstanta pegas :

$\mathrm{k}=\frac{\mathrm{W}}{\delta}=0,21 \mathrm{~kg} / \mathrm{mm}$

Beban awal terpasang (Wo) :

Wo $=$ (Panjang bebas - Panjang awal terpasang) $\mathrm{x}$ konstanta $=3,72 \mathrm{~kg}$

B. Perhitungan poros penggerak candle filter (Sigley, Mitchel, and Harahap, n.d.) adalah sebagai berikut: 
a. Daya motor $(\mathrm{P})=0,75 \mathrm{~kW}$

b. Putaran motor $(\mathrm{n} 1) \quad=480 \mathrm{Rpm}$

c. Faktor koreksi $(\mathrm{Fc}) \quad=1,5$

d. Daya rencana :

$(\mathrm{Pd})=1,5 \times 0,75=1,125 \mathrm{~kW}$

e. Momen puntir/momen rencana:

$\mathrm{T}=9,74 \times 10^{5} \frac{P_{d}}{n_{1}}=2282,8 \mathrm{Kg} . \mathrm{mm}$

f. Beban poros:

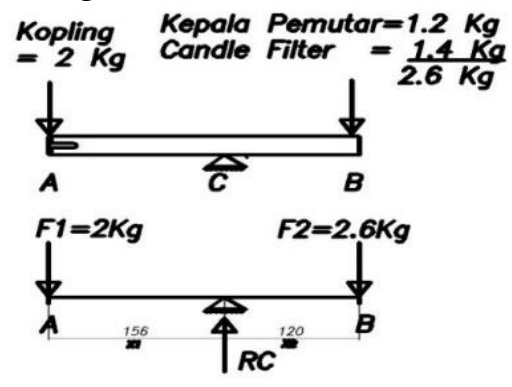

Gambar 5. Beban poros

g. Kesetimbangan beban poros

$$
\begin{aligned}
& F 1=2 \mathrm{Kg} \quad \mathrm{F} 2=2,6 \mathrm{Kg} \\
& X 1=156 \times 2=120 \mathrm{~mm} \\
& \sum M=0 \\
& M=(F 2)(\mathrm{X} 2)-(\mathrm{F} 1)(\mathrm{X} 1) \\
& M=(2,6 \times 120)-(2 \times 156) \\
& M=0
\end{aligned}
$$

h. Harga momen :

MVA $=(-F 1)(\mathrm{X} 1)$

$M V A=2 \times 156=-312 \mathrm{Kg} \cdot \mathrm{mm}$

$\mathrm{MVB}=(\mathrm{F} 2)(\mathrm{X} 2)$

$\mathrm{MVB}=2,6 \mathrm{x} 120=312 \mathrm{Kg} . \mathrm{mm}$

i. Bahan poros yang digunakan adalah S 30

$\mathrm{C}$ dengan kekuatan tarik $\sigma \mathrm{b}=48$

$\left(\mathrm{kg} / \mathrm{mm}^{2}\right)$

Dimana diketahui:

Sf1 $=6,0$ Sf2 $=1,3-3,0$

Tegangan geser yang diizinkan :

$(\tau \mathrm{a})=\sigma \mathrm{b} /(\mathrm{Sf} 1 \mathrm{x} \mathrm{Sf} 2)=2,66 \mathrm{Kg} / \mathrm{mm}^{2}$

$\mathrm{Km}=2,0$ dan $\mathrm{Kt}=1,5$

j. Diameter poros penggerak candle filter

$$
\begin{aligned}
& d_{s} \geq\left[\frac{5,1}{\tau_{a}} \sqrt{(K m \cdot M)^{2}+(K t . T)^{2}}\right]^{1 / 3} \\
& d_{s} \geq 18,25 \rightarrow \text { dipilih } \emptyset 24 \mathrm{~mm}
\end{aligned}
$$

\section{Cekam Universal}

Cekam yang digunakan adalah cekam universal (Universal chuck) berfungsi sebagai penjepit candle filter, universal chuck menjadi pilihan karena mudah dalam pemusatan (centering) sumbu candle filter dengan ukuran diameter yang berbeda.

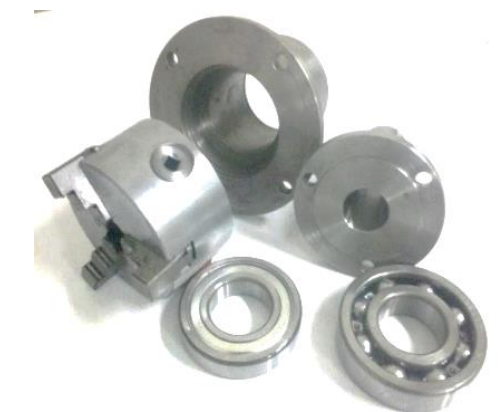

Gambar 6. Cekam universal dan asesoris

\section{Rangka}

Rangka mesin auto spray berfungsi untuk tempat atau dudukan seluruh komponenkomponen mesin auto spray, bahannya menggunakan besi siku stainless steel 50 × 50 × 5 $\mathrm{mm}$, dirancang agar kuat dan tahan terhadap korosi. Sambungannya menggunakan las listrik dengan elektroda SS Ø 2,6 mm.

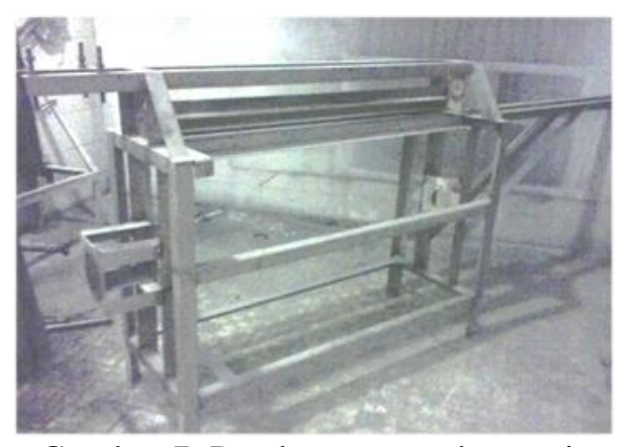

Gambar 7. Pembuatan rangka mesin

\section{Sistem kendali / kontrol}

Agar memudahkan proses spray, mesin dibantu dengan sistem kendali(Regtien 2012), alat yang digunakan dijelaskan dibawah ini: 


\section{a. Inverter}

Inverter berfungsi sebagai pengendali putaran motor listrik dengan cara merubah frekuensi $(\mathrm{Hz})$ putaran motor listrik, pada mesin auto spray ini inverter digunakan agar perubahan kecepatan putaran dapat dirubah dengan cepat sesuai kebutuhan. Inverter yang digunakan adalah siemens micromaster 440.(Siemens 2006)(Siemens 2005)(Haryanto 2011)

\section{b. Limit switch}

Limit switch merupakan jenis saklar yang dilengkapi dengan katup yang berfungsi menggantikan tombol. Prinsip kerja limit switch sama seperti saklar Push ON yaitu hanya akan menghubung pada saat katupnya ditekan pada batas penekanan tertentu yang telah ditentukan dan akan memutus saat saat katup tidak ditekan. pada mesin auto spray, limit switch terdapat pada bagian penggerak nozzle spray, gerakan nozzle spray yaitu maju dan mundur sesuai panjang candle filter, limit switch yang digunakan yaitu 2 buah untuk membatasi arah maju dan arah mundur nozzle spray.

\section{c. Timer}

TDR (Time Delay Relay) sering disebut juga relay timer atau relay penunda batas waktu, banyak digunakan dalam instalasi motor terutama instalasi yang membutuhkan pengaturan waktu secara otomatis. Relay yang menggunakan prinsip elektronik, terdiri dari rangkaian $\mathrm{R}$ dan $\mathrm{C}$ yang dihubungkan seri atau paralel, bila tegangan sinyal telah mengisi penuh kapasitor, maka relay akan terhubung.

\section{Tahap Perakitan}

Setelah komponen - komponen telah ada dan rangka mesin selesai dibuat maka selanjutnya ketahap perakitan komponen. Hal yang akan dilakukan dalam perakitan ini adalah sebagai berikut:

a. Pasang puli pada motor 1( penggerak nozzle spray ) dan mounting motor 1 pada rangka mesin

b. Pasang adaftor nozzle pada shaft screw

c. Pasang bearing F205 dua buah pada kedua ujung shaft screw

d. Pasang shaft screw pada rangka dan kencangkan baut pengikat e. Pasang sabuk-V (V-belt)

f. Pasang nozzle spray vertikal dan pelat pembawa nozzle spray horisontal pada adaftor nozzle.

g. Pasang limit switch pada rangka mesin dan setting jaraknya

h. Perakitan komponen kepala pemutar ( kepala pemutar, spring, pin, penahan, circlip, oil seal, bearing, dan bearing bracket ) setelah selesai lalu pasang kepala pemutar pada rangka mesin,

i. Pasang kopling pada shaft kepala pemutar

j. Pasang kopling pada motor 2 (Penggerak candle filter) dan mounting motor 2 pada rangka mesin

k. Perakitan komponen universal chuck yang terdiri dari universal chuck, hollow shaft, bearing, circlip.

1. Pasang universal chuck pada rangka mesin

\section{Prosedur Pengujian Mesin Auto Spray}

Uji kinerja mesin merupakan sebuah langkah pengujian terhadap sebuah mesin, uji kinerja ini bertujuan untuk mengetahui kualitas / efektifitas dari mesin.

Berikut langkah - langkah dalam melaksanakan prosedur pengujian pada mesin auto spray sebagai berikut :

a. Pasang candle filter pada mesin auto spray

b. Seting waktu proses spray pada panel ON/OFF

c. Jalankan mesin water jet dengan tekanan air 100 Bar

d. Jalankan mesin dengan menekan tombol ON pada panel

e. Setelah selesai mencapai waktu yang telah ditentukan dan mesin berhenti maka lepaskan candle filter dari mesin

f. Hitung waktu dari mulai pemasangan candle filter, proses pembersihan candle filter, sampai candle filter dilepaskan dari mesin

\section{Pengujian Kualitas Hasil Spray}

Pengujian kualitas hasil spray, menggunakan metode perhitungan berat sampel uji candle filter yang dibersihkan, yaitu (Total deposit $=$ Berat setelah pembersihan dikurangi berat asli dari candle filter). 


\section{HASIL DAN PEMBAHASAN}

Setelah dilakukan pengujian kinerja mesin, mesin auto spray ini memiliki kelebihan dan kekurangan sebagai berikut :

\section{Kelebihan Mesin Auto Spray}

Keuntungan / Kelebihan mesin auto spray yaitu tenaga penggerak manusia (manual) digantikan dengan tenaga penggerak motor listrik / mesin.

\section{Kelemahan Mesin Auto Spray}

Setelah dilakukan pengujian mesin, masih didapatkan kelemahan sebagai berikut :

a. Gerakan maju mundurnya nozzle spray vertikal kurang stabil / goyang dikarenakan getaran yang ditimbulkan baik oleh tekanan air maupun putaran poros.

b. Belum adanya casing yang menyebabkan pantulan air pada waktu spray menyebar ke segala arah, sehingga menyebabkan operator kurang nyaman dalam bekerja.

Tabel 3. Perbandingan spray manual dan auto

\begin{tabular}{|l|c|c|}
\hline Parameter & Manual & Auto spray \\
\hline Operator & $\begin{array}{c}\text { Operator terus } \\
\text { menerus berada } \\
\text { dilokasi } \\
\text { melakukan } \\
\text { pembersihan } \\
\text { (spray })\end{array}$ & $\begin{array}{c}\text { Operator dapat } \\
\text { meninggalkan } \\
\text { tempat pembersihan } \\
\text { (spray) selama } \\
\text { waktu seting }\end{array}$ \\
\hline Waktu & Tidak dapat diatur & $\begin{array}{c}\text { Waktu diatur } \\
\text { dengan pasti }\end{array}$ \\
\hline Gerakan & $\begin{array}{c}\text { Gerakan tidak } \\
\text { pasti }\end{array}$ & Gerakan Pasti \\
\hline $\begin{array}{l}\text { Penempatan } \\
\text { candle filter }\end{array}$ & Mudah & Mudah \\
\hline Kecepatan & Lama & cepat \\
\hline
\end{tabular}

Hasil perancangan adalah berupa mesin auto spray untuk candle filter. Alat tersebut mempunyai spesifikasi sebagai berikut :
Tabel 4. Spesifikasi mesin auto spray

\begin{tabular}{|l|l|}
\hline Nama alat & Mesin auto spray \\
\hline Dimensi rangka (P x L x T) & 3005 x 515 x 1215 \\
\hline Candle Filte r : & \\
\hline Panjang & $1000-1020 \mathrm{~mm}$, \\
\hline Diameter & $\varnothing 48-58,8 \mathrm{~mm}$ \\
\hline Bahan Rangka : & Stainless steel 304 \\
\hline Kecepatan Putaran : & \\
\hline Poros penggerak & $596,1 \mathrm{Rpm}$ \\
\hline Poros pemutar & $480 \mathrm{Rpm}$ \\
\hline Transmisi : & \\
\hline Poros penggerak & Puli dan sabuk-v \\
\hline Poros pemutar & Kopling flens kaku \\
\hline Daya dan Putaran motor : & \\
\hline Motor penggerak nozzle & $0,75 \mathrm{~kW}, 1395 \mathrm{Rpm}$ \\
\hline Motor pemutar candle & $0,75 \mathrm{~kW}, 3000 \mathrm{Rpm}$ \\
\hline Sistem kendali : & \\
\hline Frekuensi ( Hz) motor & Inverter \\
\hline Waktu & Timer / TDR \\
\hline Pembatas Jarak & Limit Switch \\
\hline Start / Stop & Tombol ON / OFF \\
\hline
\end{tabular}

\section{Kualitas Hasil Spray}

Kualitas hasil spray yang didapat dari perhitungan berat candle filter dapat dilihat pada Tabel 5 bahwa proses spray untuk candle filter yang dilakukan menggunakan mesin mendapatkan hasil yang lebih baik dibandingkan pembersihan dengan cara manual.

Jumlah candle filter yang diuji yaitu sebanyak 40 buah yang diberi kode AF1 sampai dengan AF40, lalu hasil uji dirata-rata sehingga didapat kualitas hasil pembersihan menggunakan mesin auto spray.

Dari hasil pengujian yang dapat dilihat pada Tabel 5, terdapat partikel seberat 5,36 gram pada proses spray menggunakan mesin dan 23,6 gram dengan cara manual. Hasil ini didapat dengan cara menimbang candle filter setelah dilakukan pembersihan lalu dikurangi berat asli dari candle filter, hasil yang baik ini terjadi dikarenakan mesin auto spray melakukan pemutaran candle filter saat pembersihan berlangsung, sehingga membantu mengeluarkan partikel-partikel yang menempel pada candle filter. 
Tabel 5. Hasil uji berat candle filter

\begin{tabular}{|c|c|c|c|}
\hline Candles No & $\begin{array}{c}\text { Original } \\
\text { (gram) }\end{array}$ & $\begin{array}{c}\text { Manual } \\
\text { (gram) }\end{array}$ & $\begin{array}{c}\text { Auto } \\
\text { (gram) }\end{array}$ \\
\hline AF01 & 1972.43 & 1993.74 & 1977.48 \\
\hline AF02 & 1967.05 & 1994.17 & 1971.86 \\
\hline AF03 & 1991.50 & 2016.54 & 1997.75 \\
\hline AF04 & 1997.33 & 2023.07 & 2002.89 \\
\hline AF05 & 1967.05 & 1988.16 & 1972.44 \\
\hline AF06 & 1968.40 & 1987.74 & 1972.55 \\
\hline AF07 & 2001.35 & 2030.59 & 2006.74 \\
\hline AF08 & 2000.90 & 2020.52 & 2005.14 \\
\hline AF09 & 1967.05 & 1989.76 & 1971.60 \\
\hline AF10 & 1981.51 & 2004.71 & 1986.82 \\
\hline AF11 & 1958.95 & 1977.42 & 1966.80 \\
\hline AF12 & 1974.89 & 2004.09 & 1981.24 \\
\hline AF13 & 2001.60 & 2028.06 & 2007.35 \\
\hline AF14 & 1987.98 & 2012.06 & 1994.38 \\
\hline AF15 & 2030.15 & 2049.49 & 2035.35 \\
\hline AF16 & 2001.46 & 2023.20 & 2007.92 \\
\hline AF17 & 2032.90 & 2053.60 & 2040.66 \\
\hline AF18 & 2037.30 & 2061.08 & 2042.12 \\
\hline AF19 & 2028.75 & 2056.98 & 2036.15 \\
\hline AF20 & 2002.22 & 2025.43 & 2006.47 \\
\hline AF21 & 2029.55 & 2056.84 & 2034.79 \\
\hline AF22 & 1973.77 & 1996.02 & 1979.80 \\
\hline AF23 & 2008.55 & 2035.35 & 2012.40 \\
\hline AF24 & 1979.68 & 1999.69 & 1984.47 \\
\hline AF25 & 1970.45 & 1991.86 & 1975.21 \\
\hline AF26 & 2011.25 & 2034.73 & 2015.54 \\
\hline AF27 & 1977.87 & 2000.14 & 1985.43 \\
\hline AF28 & 1991.28 & 2012.54 & 1996.62 \\
\hline AF29 & 1983.88 & 2008.06 & 1987.67 \\
\hline AF30 & 1972.15 & 1993.15 & 1977.77 \\
\hline AF31 & 2031.38 & 2053.94 & 2036.45 \\
\hline AF32 & 1973.89 & 1993.18 & 1978.50 \\
\hline AF33 & 1966.23 & 1988.91 & 1970.98 \\
\hline AF34 & 1982.15 & 2006.78 & 1987.93 \\
\hline AF35 & 1982.28 & 2002.18 & 1987.51 \\
\hline AF36 & 1994.30 & 2024.38 & 1999.62 \\
\hline AF37 & 1998.83 & 2028.26 & 2004.09 \\
\hline AF38 & 1999.20 & 2025.63 & 2003.42 \\
\hline AF39 & 1978.18 & 2004.09 & 1982.67 \\
\hline AF40 & 1975.25 & 1998.70 & 1980.86 \\
\hline Rata-rata & 1991.27 & 2014.87 & 1996.64 \\
\hline Total Deposit= & $\mathbf{2 3 . 6 0}$ & $\mathbf{5 . 3 6}$ \\
\hline
\end{tabular}

\section{Efisiensi Waktu Proses Spray}

Efisiensi yang dihasilkan dari perancangan mesin auto spray dapat dilihat di Tabel 3. yaitu dengan membandingkan pengerjaan spray manual dan sesudah di lakukan perancangan mesin auto spray.

Pada Tabel 6. Parameter utama dari efisiensi yang dihasilkan yaitu pengerjaan spray yang awalnya dilakukan dua kali yaitu pertama pembersihan bagian luar candle filter lalu kedua pembersihan bagian dalam, menjadi satu kali pengerjaan, kemudian efisiensi berikutnya yaitu pada saat memutar candle filter sewaktu pembersihan, dari hasil wawancara dan pengamatan, pengerjaan spray dengan cara manual memerlukan waktu keseluruhan yaitu 25 menit, sedangkan setelah menggunakan mesin, pengerjaan cukup dilakukan satu kali, lalu candle filter juga ikut berputar, agar pembersihan merata ke semua permukaan bagian dalam dan bagian luar, yang memerlukan waktu 10 menit. Dari perhitungan waktu pengerjaan spray terdapat selisih waktu yaitu 15 menit, sehingga efisiensi waktu dapat dihitung yaitu (15 menit / 25 menit) $\mathrm{x} 100))=60 \%$.

Tabel 6. Perbandingan waktu spray

\begin{tabular}{|c|c|c|c|c|c|}
\hline & \multirow{2}{*}{$\begin{array}{l}\text { Jumlah } \\
\text { /3 bulan }\end{array}$} & \multicolumn{2}{|c|}{ Spray manual } & \multicolumn{2}{|c|}{ Auto spray } \\
\hline & & $\begin{array}{c}\text { Waktu } \\
\text { (Menit) }\end{array}$ & $\begin{array}{c}\text { Total } \\
\text { (Menit) }\end{array}$ & $\begin{array}{l}\text { Waktu } \\
\text { (Menit) }\end{array}$ & $\begin{array}{c}\text { Total } \\
\text { (Menit) }\end{array}$ \\
\hline Pre-poli & 423 & 25 & 10575 & 10 & 4230 \\
\hline Rama 2 & 19 & 25 & 475 & 10 & 190 \\
\hline PSF1 & 28 & 25 & 700 & 10 & 280 \\
\hline PET & 480 & 25 & 12000 & 10 & 4800 \\
\hline POLY3 & 60 & 25 & 1500 & 10 & 600 \\
\hline POY & 50 & 25 & 1250 & 10 & 500 \\
\hline PSF3 & 30 & 25 & 750 & 10 & 300 \\
\hline
\end{tabular}

\section{KESIMPULAN}

Perancangan mesin auto spray ini dapat disimpulkan bahwa proses spray dengan menggunakan mesin dapat menghemat waktu sampai $60 \%$ yang dihitung dari selisih waktu sebesar 15 menit dari sebelumnya yaitu lama waktu proses spray manual adalah 25 menit menjadai 10 menit jika menggunakan mesin, proses spray menjadi mudah karena mesin didesain otomatis mengerjakan spray, operator hanya memasang dan melepas filter di mesin, waktu serta putaran dapat di setel sesuai kebutuhan karena menggunakan inverter dan limit switch serta timer. Rangka mesin didesain tahan korosi, dipilih jenis material siku SS 304 , mesin di desain mampu melakukan spray untuk berbagai macam ukuran candle filter karena penjepitnya 
menggunakan universal chuck dan untuk menahan beban aksial menggunakan spring sehingga memudahkan dalam memasang dan melepaskan candle filter. Dari hasil uji kualitas pembersihan didapat hasil yang lebih baik jika menggunakan mesin dibandingkan dengan cara manual, dari jumlah 40 buah sampel yang uji terdapat nilai ratarata partikel 5,36 gram pada proses spray menggunakan mesin dan 23,6 gram dengan cara manual. Mengenai studi kelayakan dan analisa tekno ekonomi akan dibahas pada tulisan selanjutnya.

\section{UCAPAN TERIMA KASIH}

Penulis pada kesempatan ini mengucapkan terimakasih kepada Bapak A.Hanan dan Head of Departement Maintenance yang telah membantu dalam penelitian, sehingga penelitian berjalan dengan baik.

\section{DAFTAR PUSTAKA}

Bitar. 2019. "Pengertian Hidrolisis." 2019.

Cirqueira, Samirys Sara Rodrigues, Eduardo Hiromitsu Tanabe, and Mônica Lopes Aguiar. 2019. "Experimental Investigation of Particle Deposition in Filter Media during Filtration Cycles with Regeneration by Pulse Jet Cleaning." Process Safety and Environmental Protection 127: 288-98. https://doi.org/10.1016/j.psep.2019.05.013.

Guha, Anirban, Ronald M. Barron, and Ram Balachandar. 2011. "An Experimental and Numerical Study of Water Jet Cleaning Process." Journal of Materials Processing Technology $211 \quad$ (4): $\quad 610-18$. https://doi.org/10.1016/j.jmatprotec.2010.11 .017 .

Haryanto, Heri. 2011. "Pembuatan Modul Inverter Sebagai Kendali Kecepatan Putaran Motor Induksi." Rekayasa 4 (1): 9-20.

Hayashi, Kazutaka, Kazumasa Douhara, and Genro Kashino. 2014. "Evaluation of the Bubble Point Test of a 0.22-Mm Membrane Filter Used for the Sterilizing Filtration of PET Radiopharmaceuticals." Annals of Nuclear Medicine 28 (6): 586-92. https://doi.org/10.1007/s12149-014-0830-0.

Jo Joong-yeon et al. 2013. Cleaning method of a polymer filter for producing a polyester, issued 2013.

Nvbop. 2018. "Bubble Point Testing Procedure."
Raehse, Wilfried Dr et al. 1989. Method and apparatus for separating and cleaning cellulose ethers and other cellulose derivatives. DE3729268A1, issued 1989.

Regtien, Paul P.L. 2012. "Sensors for Mechatronics." In Sensors for Mechatronics. The Netherlands: Elsevier. https://doi.org/10.1016/B978-0-12-3914972.00001-7.

Siemens. 2005. Micromaster $440(0,12 \mathrm{KW}-250$ $K W)$ Operating Instructions (Compact).

. 2006. Micromaster 440 Parameter List.

Sigley, Joseph E, Larry D Mitchel, and Gandhi Harahap. n.d. Perencanaan Teknik Mesin. 4th ed.

Sularso, and K Suga. 1996. Dasar Perencanaan Dan Pemilihan Elemen Mesin. Edited by Pradinya Paramita. Jakarta: Erlangga.

Suwandi, Agri, Eka Maulana, and Febrian Dio Rhapsody. 2017. "Perancangan Sepeda Statis Penghasil Energi Listrik Yang Ergonomis.” Flywheel III (2): 24-31.

Ushiki, K., and C. Tien. 1989. "Analysis of Filter Candle Performance." Powder Technology 58 (4): 243-58. https://doi.org/10.1016/00325910(89)80051-8. 